\title{
Comparison between the lifestyles of university students with and without premenstrual syndromes
}

\author{
Maryam Mohebbi ${ }^{1}$, Sedigheh Amir Ali Akbari², Zohre Mahmodi ${ }^{3}$, Malihe Nasiri ${ }^{4}$
}

\author{
${ }^{1}$ M.Sc. of Midwifery, School of Nursing and Midwifery, Shahid Beheshti University of Medical Sciences, Tehran, \\ Iran \\ ${ }^{2}$ Ph.D., Department of Midwifery, School of Nursing and Midwifery, Shahid Beheshti University of Medical \\ Sciences, Tehran, Iran \\ ${ }^{3}$ Ph.D., Assistant Professor of Social Determinant of Health, Department of Midwifery, School of Nursing and \\ Midwifery, Alborz University of Medical Sciences, Karaj, Iran \\ ${ }^{4}$ Ph.D. of Biostatistics, Assistant Professor, Department of Basic Sciences, School of Nursing and Midwifery, \\ Shahid Beheshti University of Medical Sciences, Tehran, Iran
}

\section{Type of article: Original}

\begin{abstract}
Introduction: Premenstrual syndrome is a common disorder in reproductive age and it is associated with decreased quality of life in women. In view of various factors contributing to outbreak of PMS (premenstrual syndrome) among women, the present study intended to compare lifestyles of university students with and without premenstrual syndromes living in dormitories of Qazvin University of Medical Sciences in 2015.

Methods: The descriptive cross-sectional study recruited 200 university students with and without PMS from students living in dormitories. Data were collected using questionnaires of premenstrual symptoms, questionnaires for diet, perceived stress, and unhealthy behavior. Data were analyzed using descriptive statistics, independent samples t-test, Mann-Whitney, Chi-square, and logistic regression in SPSS version 23.

Results: The results showed that nutrition style $(\mathrm{p}=0.001)$, perceived stress $(\mathrm{p}=0.001)$, and exposure to passive tobacco smoke $(\mathrm{p}=0.001)$ were different between the two groups. Logistic regression analysis showed that nutrition style $(\mathrm{p}=0.001, \mathrm{OR}=0.861)$, exposure to passive tobacco smoke $(\mathrm{p}=0.008, \mathrm{OR}=2.059)$, and stress $(\mathrm{p}=0.001, \mathrm{OR}=1.088)$ were different in both groups.

Conclusion: The research results proved that lifestyle, especially healthy eating habits, and decreasing stress and unhealthy behavior can influence PMS. Therefore, interventions are recommended to improve PMS symptoms.

Keywords: Lifestyle, Perceived stress, Premenstrual syndromes, Unhealthy behaviors, Nutrition
\end{abstract}

\section{Introduction}

Premenstrual syndrome (PMS) is one of the most common disorders experienced at various levels by $85-90 \%$ of women of reproductive age (1-4). The symptoms are sufficient to impair daily relationships and activities. It is estimated that $30-40 \%$ of women would require medical treatment and $5 \%$ of women of productive age qualify for diagnosis of premenstrual dysphoric disorder (PMDD) (4, 5-7). The symptoms are diagnosed by records of two complete menstrual cycles (5, 8-9). PMS includes a diverse range of physical and behavioral symptoms. The most common clinical symptoms are abdominal bloating, fatigue, breast pain, and headache while behavioral symptoms include instability, irritability, depression, increased appetite, forgetfulness, and difficulty in concentration. These symptoms are significant during the last 7-10 days of the cycle (9). PMS impairs job or academic performances. PMS also has economic consequences because of increasing absenteeism, decreasing academic efficiency and performance of students. Family disputes are another consequence (3). The prevalence of PMS has been reported as 37.5\% among Arabic, 17.5\% among Japanese, 41\% among American, 43.2-52.2\% among Brazilian, and 10-12\% among European women while the highest rate of PMS prevalence belongs to Asian women with $98 \%(10)$.

\section{Corresponding author:}

Dr. Sedigheh Amir Ali Akbari, Shahid Beheshti University of Medical Sciences, Tehran, Iran.

Tel: +98.2188202512, Fax: +98.2188202512, Email: sedaliakbari@gmail.com

Received: August 21, 2016, Accepted: January 16, 2017, Published: June 2017

iThenticate screening: December 28, 2016, English editing: February 18, 2017, Quality control: April 02, 2017

(C) 2017 The Authors. This is an open access article under the terms of the Creative Commons Attribution-NonCommercialNoDerivs License, which permits use and distribution in any medium, provided the original work is properly cited, the use is non-commercial and no modifications or adaptations are made. 
Ramezani Tehrani et al. reported 52.9\% prevalence of premenstrual syndrome in Iran (11). The uncertainty about the main causing agent of PMS is one of its complexities, therefore, a combination of factors might contribute to its emergence (12). There is no single treatment for PMS that has been globally accepted and there are different treatments such as changes in lifestyle, education, stress management (massage, reflex therapy, yoga), sport, herbal medicines, selective serotonin reuptake inhibitors (SSRIs), and anti-depression drugs (13). In view of the adverse effects of medical and surgical treatments, non-medicinal treatments and complementary medicine are more attractive for researchers (14). PMS symptoms, often seen as PMS, dysmenorrhea, or gynecological problems, can be influenced by young women's lifestyle and activities (15). The World Health Organization (WHO) has studied healthy behaviors in 35 countries. The results indicated that $60 \%$ of quality of life and people's health depended on their lifestyle and individual behavior. The WHO has defined promotion of a healthy lifestyle and decrease in harming factors to people's health as one of its objectives in 'Healthy People 2020'. These harming factors include inappropriate physical activities, unhealthy diet, damaged personal relationship, alcohol and other illicit drugs use (16). Lifestyle modification, coined by Alfred Adler the Austrian psychiatrist, is an important concept often used for expressing people's way of life, and is defined as a wide range of values, beliefs, and social activities and influence people's health. Lifestyle includes different dimensions such as diet, physical activity, self-care, smoking, alcohol and illicit drug use, social relationships, and stress control (17). Serotonin is responsible for formation and control of many physiological, behavioral, and mood reactions considering the fact that PMS symptoms are similar to a situation in which neurotransmitter serotonin decreases $(14,18)$. Through various mechanisms, thiamine, vitamin B, niacin, riboflavin, vitamin B6, folate, and vitamin B12 are involved in body metabolism by neurotransmitter. Riboflavin is necessary for activating vitamin B6, a cofactor in producing serotonin from tryptophan, as its deficiency might lead to a decrease in tryptophan, and would consequently decrease serotonin production. Vitamin B12, vitamin B6, and folate form S-adenosylmethionine and tetrahydropterin, which are both essential for dopamine and serotonin metabolism $(18,19)$. Some studies have reported efficacy of vitamin B6 in decreasing severity of PMS (20,21). Stress creates mood changes through decreasing brain beta-endorphin and increasing adrenal cortisol. It is also one of the effective mechanisms in creating psychological symptoms and mood changes (22). Stress can also increase unhealthy behavior such as alcohol and tobacco use (23). Smoking can affect emergence of PMS by influencing estrogen-progesterone, androgen, and gonadotropin levels. Smoking is more common in PMS though it is not clear whether it is an underlying cause of PMS, or if women with PMS smoke to alleviate the symptoms (24). The present study intended to compare lifestyle of university students with and without PMS who were living in dormitories of Qazvin University of Medical Sciences in 2015 in view of the following facts: high prevalence of PMS, lack of a known cause and treatment for it, lack of sufficient studies about the impact of different lifestyles among people with and without PMS, the close relationship between lifestyle and emergence or progress of many chronic diseases.

\section{Material and Methods}

\subsection{Research design and participants}

This cross-sectional study was conducted on 200 students living in dormitories affiliated to Qazvin University of Medical Sciences in 2015. The inclusion criteria were as follows: aged 18-38 years, Iranian nationality, ability to communicate in Persian, living in a dormitory, no known psychological or chronic diseases, no medication for depression, contraception, or obesity, not pregnant or lactating, no specific diets or medications, no stressful life events such as death of loved ones, and no surgery. The sample volume was calculated as 100 per group (CI 95\%, type I error 0.05 , test power $90 \%$, and effect size 0.5 ).

\subsection{Instrument}

The several questionnaires were filled out for demographic data, dietary recall, perceived stress and unhealthy behavior through self-reporting. The data collection tools included the following questionnaires: provisional diagnosis of PMS, Daily Record of Severity of Problems (DRSP), dietary recall, unhealthy behavior, perceived stress, and demographic data. Additionally, a weighing scale and tape measure were used. The demographic data included personal and social characteristics, age, weight, height, body mass index (BMI), job, marital status, husband's job if applicable, husband's level of education if applicable, monthly family income, menstrual history including menstrual cycle interval and length of menstrual bleeding. The presence of five symptoms of PMS in provisional diagnosis of PMS questionnaire during the last seven days of menstrual cycle was considered as being diagnosed with PMS. Then DRSP was given to the samples, with comprehensive instructions, to be filled out for two consecutive menstrual cycles. DRSP contains 19 symptoms extracted from DSM-IV criteria and samples were asked to mark the severity of symptoms with 0 (not present), 1 (slight), 2 (moderate), or 3 (severe). These scores were converted into a 0-100 scale in statistical calculation and the severity of symptoms was categorized into three 
groups of slight (0-33), moderate (34-66) and severe (67-100). Jafar Nejad et al. and Mahmoodi et al. assessed the content validity of DRSP, and its reliability was reported as correlation coefficient of 0.92 by Freeman et al. (18, 22, 25). Jafar Nejad et al. and Mahmoodi et al. reported its reliability as 0.87 and 0.83 respectively and we found it as 0.85. The Questionnaire for diet was developed by Sedighi et al. in 2015 and contains 28 items. The research samples initially read the instructions which explain different units of food groups before answering the questions. The frequency of consumption was calculated in both groups in a 0-112-point scale while a higher score indicated a better nutritional status. This survey contains 16 positive and 12 negative dietary related questions. The scoring ranges from 4 (every day) to 0 (never) for positive questions while it is scored reversed for negative items. This scale was converted into 0-100 scale in statistical calculations as 0-33 indicated poor nutritional status, 34-66 indicated moderate nutritional status, and 67-100 indicated good nutritional status. The validity of the questionnaire was evaluated by Sedighi et al. using content validity and its reliability was reported with Cronbach's alpha coefficient of 0.82 by Sedighi et al. (26). The unhealthy behavior was measured through an eight-item survey with a total score of 22. Because only two people in each group had unhealthy behavior, no statistical tests were performed on this item; however, frequency of passive tobacco smoke was assessed by the following options: never, 1-2 times a week, 3-4 times per week, and through the week. Its validity was assessed by Sedighi et al. using content validity and Sedighi et al. reported its reliability as 0.90 using retest method. The 14-item Perceived Stress Scale (PSS-14) was used with seven negative questions indicative of the poor coping ability and seven positive items indicative of good coping ability. Answers range on a 5-point Likert scale with never (0), to most of the time (4) (27). The positive items (Items: 3, 5, 6, 7, 9, 10, 13) were scored in reverse. The lowest point was 0 and the highest was 56; higher scores were indicative of higher perceived stress. The validity of this scale was tested through content validity in previous studies (28-30). The reliability of PSS has been assessed using internal consistency in three different studies with Cronbach's alpha of 0.84-0.86 (31). The Cronbach's alpha was reported as 0.88 , and 0.83 by Velsmoro et al. and Hazavehei et al. respectively $(29,32)$. Bastani et al. reported acceptable Cronbach's alpha of 0.81 in measuring its reliability and internal consistency (33). Vahedian Azimi et al. reported 0.89 for Cronbach's alpha (30). An Italian-made tape measure (Leica) and a German-made scale (Seca) were used. The reliability of the scale was first tested by a 1-kg standard weight and the scale was then calibrated with the same weight after ten weightings, according to manufacturer's instructions. The reliability of the tape measure was assessed by comparing with the standard non-elastic weather-resistance tape measure.

\subsection{Data collection}

This cross-sectional study was conducted after obtaining introduction letters and approval from the Ethics Committee of Shahid Beheshti University of Medical Sciences and Qazvin University of Medical Sciences. The samples were all female students living in dormitories affiliated to Qazvin University of Medical Sciences in 2015. PMS symptoms were recorded on a daily basis in the PDSD form for two consecutive months and PMS was diagnosed using criteria defined by the Psychiatric Association. These criteria included having five out of the following ten symptoms such that at least one symptom was from the first four: 1- mood and affective instability such as unreasonable crying, 2- anger and bad temper, 3-anxiety and nervousness, 4- fatigue and disappointment, 5lack of interest in doing daily activities, 6- fatigue and lethargy, 7- difficulty in concentrating, 8- insomnia or hypersomnia, 9- somatic symptoms such as breast tenderness, headache, muscle and joint pain, and weight gain. Hence, non-probability convenience sampling method was used to select 200 students. Written consent forms were obtained and students were ensured of confidentiality of their information after they were briefed on the research. The questionnaires were filled out by the researcher in about 10 minutes. Sampling continued until enough samples were selected.

\subsection{Ethics}

This research was approved by the Ethics Committee of Nursing and Midwifery Department of Shahid Beheshti University of Medical Sciences.

\subsection{Statistical analysis}

The collected data were analyzed in SPSS version 23 at an alpha level of 0.05 . The descriptive data were reported using central tendency and dispersion indices (mean value and standard deviation), and distribution frequency. Data with normal and non-normal distribution were analyzed using samples t-test and Mann-Whitney test, respectively. Chi-square test was used for qualitative data and logistic regression was employed for general assessment. 
http://www.ephysician.ir

\section{Results}

This research recruited 100 students with PMS and 100 students without PMS. The mean BMI was measured as 22.27 and $23.90 \mathrm{~kg} / \mathrm{m} 2$ in PMS and non-PMS groups, respectively and their differences were significant. The demographic data showed no significant differences between the two groups in terms of age at menarche, length of menstrual bleeding, marital status, job, husband's job, and husband's level of education; however, monthly income was significantly different $(\mathrm{p}=0.02)$. The menstrual history had no significant difference in terms of length of bleeding and age at menarche but differences in menstrual intervals were significant $(p=0.004)$ (Table1). The results of independent t-test showed that all three psychological, behavioral, and physical symptoms in the PMS group was higher than those in the non-PMS group; behavioral symptoms scored higher (Table2). The results showed a significant difference between the two groups in terms of nutrition, passive smoking and perceived stress $(p=0.001)$. The mean score of nutrition was 59.08 and 61.75 and the mean score of perceived stress was 49.62 and 43.23 in the PMS group and the healthy group. The mean rank of passive smoking was 109.88 in PMS group and 91.13 in nonPMS group. Logistic regression analysis showed that nutrition style $(\mathrm{p}=0.011$, OR=0.861), passive smoking $(\mathrm{p}=0.008, \mathrm{OR}=2.059)$, and perceived stress $(\mathrm{p}=0.001, \mathrm{OR}=1.088)$ were different in both groups $($ Table 3$)$.

Table 1. Compares the demographic and obstetric intervention in patients with and without PMS

\begin{tabular}{|l|l|l|l|l|}
\hline Variable (Majority) & With PMS & Without PMS & Test & p-value \\
\hline BMI (kg/m ${ }^{2}$ ) (18.5-24.9) & 87 & 67 & t-test & 0.001 \\
\hline Menarche age (13 year) & 30 & 6 & t-test & 0.056 \\
\hline Menstruation time (5-7 day) & 76 & 82 & t-test & 0.88 \\
\hline Marital status (married) & 52 & 46 & Chi-square & 0.77 \\
\hline Occupation (unemployed) & 89 & 94 & Chi-square & 0.20 \\
\hline Husband's occupation (self-employed) & 27 & 23 & Chi-square & 0.37 \\
\hline Age (18-38 year) & 45 & 28 & Mann-Whitney U & 0.009 \\
\hline Monthly Income (1000000-1500000 Toman) & 55 & 17 & Mann-Whitney U & 0.02 \\
\hline Menstruation interval (21 - 35 years) & 62 & 66 & Mann-Whitney U & 0.004 \\
\hline Husband's education (college) & 29 & 17 & Mann-Whitney U & 0.15 \\
\hline
\end{tabular}

Table 2. Compare severity of symptoms (mood, behavioral, physical) in patients with and without premenstrual syndrome

\begin{tabular}{|l|l|l|l|l|}
\hline Symptoms & With PMS & Without PMS & Test & p-value \\
\hline Mood & $8.01 \pm 3.10$ & $3.84 \pm 2.57$ & t-test & $<0.001$ \\
\hline Behavioral & $12.21 \pm 4.90$ & $5.14 \pm 3.21$ & t-test & $<0.001$ \\
\hline Physical & $8.32 \pm 4.48$ & $4.04 \pm 2.44$ & t-test & $<0.001$ \\
\hline Total & $9.51 \pm 3.88$ & $4.34 \pm 1.72$ & t-test & $<0.001$ \\
\hline
\end{tabular}

Table 3. Calculating Regression coefficients of lifestyle and demographics in the two groups

\begin{tabular}{|l|l|l|l|l|}
\hline Variable & OR & B & p-value & CI (95\%) \\
\hline Age $($ years $)$ & 0.910 & -0.094 & 0.020 & $0.841-0.986$ \\
\hline BMI $\left(\mathrm{kg} / \mathrm{m}^{2}\right)$ & 0.741 & -0.299 & 0.001 & $0.628-0.875$ \\
\hline Interval menstruation & 0.328 & -1.116 & 0.004 & $0.154-0.699$ \\
\hline Monthly income & 2.689 & 0.989 & 0.001 & $1.624-4.453$ \\
\hline Nutrition & 0.861 & -0.149 & 0.001 & $0.787-0.942$ \\
\hline Perceived stress & 1.088 & 0.084 & 0.001 & $1.042-1.135$ \\
\hline Exposure to passive tobacco smoke & 2.059 & 0.722 & 0.008 & $1.203-3.522$ \\
\hline
\end{tabular}

\section{Discussion}

The results of the present study showed that lifestyle in domains of nutrition, perceived stress, and unhealthy behavior were different between PMS and non-PMS groups. Nutritional habits are one of the lifestyle dimensions that influence physical health status (34). Our study results showed that the mean consumed amount of various foods was significantly different between the two groups. Few studies have investigated lifestyle and nutritional habits and their association with PMS (35-36). Increases in carbohydrate consumption increase serotonergic activity and improve PMS symptoms (37). Mahmoodi et al. found that adding carbohydrate, either as food or as dietary supplement could decrease the severity of mood, behavioral, and physical symptoms and severity of PMS in general (18). Decreasing consumption of salty or high-caffeine foods, and eating low-fat high-fiber food improve symptoms 
by decreasing estrogen level (13). Neal and Bernard also confirm these results (38). The study by Cross et al. indicated that women with PMS consumed a more significant amount of fat, carbohydrate, simple sugars and received significantly less amount of protein before menstruation in comparison with women without PMS. The analysis of consumed food showed that high-calorie foods such as cakes, cereals, dessert, and sweet foods increased during the days before menstruation (39). Gold et al. discovered a significant relationship between an increase of 500 calories to daily calorie intake and 50\% increase in carbohydrate consumption, and diagnosis with PMS (40). Bakhshani et al. studied two groups of students with and without PMS. The results showed that the mean consumption of dairy products (milk, yogurt, cheese) and fruits and vegetables was significantly higher in the PMSfree group. The research results obtained by Bakhshani showed that monthly consumption of bread, rice, pasta, and potato as complex carbohydrates, as well as mean monthly consumption of honey and sugar as simple carbohydrate, did not result in any significant difference between the groups with and without PMS. This was not aligned with present study results which indicated that mean consumption of fruits, vegetables, bread and cereal, rice, pasta, whole wheat bread, red meat, fish, nuts and oil seeds, milk, yogurt, low fat dairy products, beans, chicken, carbonated drinks, salty foods, solid and animal fat was higher in the group without PMS. Consumption of canned and restaurant food, cheese, high fat dairy products, sugar, mayonnaise, sausages and cold cuts, chicken wings and neck, chips and snacks, fried foods, cooking oil was lower in PMS-free group in comparison with the PMS group (1). Seedhom et al. studied factors associated with lifestyle and PMS among university students. Their study showed that there was a significant correlation between increasing PMS symptoms and positive family history, obesity, low consumption of fruit and vegetables, consumption of fast foods and caffeine (41). Tabarroki et al. showed that intake of energy and macronutrients in the luteal phase of women with PMS was significantly higher than in the follicular phase (42). This is contrary to study results of Trout et al. who did not observe any significant difference in energy intake during the two menstruation phases of women with PMS (43). Furthermore, the results of the Tabarroki study are not aligned with findings of Bryan. Bryan et al. reported lower energy and macronutrients consumption during the pre-menstrual phase than post-menstrual phase (44). Consulting and training for healthy eating and nutrition seem necessary for women with PMS given the fact that many studies have confirmed the effectiveness of dietary changes on hormonal, metabolic, and clinical status of women with PMC and the contributing factors of obesity and poor nutrition to PMS. Stress is an event or situation that affects psychological-physical aspects (45). High levels of stress have several consequences including physical and mental disorders such as anxiety, depression, and sleep disorders (46). Stress influences the regular secretion of hypothalamus and pituitary hormones (47). Zarei and Bazzazian discovered a positive significant correlation between mental pressure and PMS (48). Lustyk et al. reported a significant relationship between stress scores and severity of PMS symptoms such that the higher levels of stress were associated with more severity of symptoms, which is aligned with the present study results. Stress influences mood through decreasing brain beta-endorphins and increasing adrenal cortisol, which is another effective mechanism for changes in psychological and mood symptoms in people with PMS (49). Cheng et al. believe that stress causes PMS and increases severity of its symptoms. They also reported a significant correlation between these two variables (50). Gibbs et al. expressed effectiveness of stress decreasing strategies in improving PMS symptoms (51). Armand and Talaee showed that efficient coping strategies and stress management could significantly reduce stress and consequently PMS symptoms in women with PMS. Cognitive-behavioral interventions of stress management can increase people's capability in decreasing stress and proper adaptability to stressful situations, and thus can decrease stress symptoms (52). Therefore, providing stress management and life skill training, which could reduce stress, depression and anxiety symptoms of people in general, to women with PMS could be helpful too. Jafar-Nejad et al. showed that stress scores in university students with PMS were significantly lower than those of students without PMS symptoms. Increases in severity of PMS symptoms was positively and significantly correlated with increases in stress score (22). Takeda et al. observed a correlation between severity of PMS and natural disaster-induced PTSD (53). This is aligned with studies of Khodayari-Fard and Parand who considered higher incidence of PTSD in women due to their biological differences. Seedhom et al. found that passive smoking had a significant relationship with PMS $(\mathrm{p}=0.006)$ which is aligned with Gold et al. study $(\mathrm{p}=0.001)$ (41). Sakai and Ohashi reported that estrogen increases nicotine metabolism in women in comparison with men but cytochrome activity, which is initially responsible for nicotine metabolism, is not affected by the menstrual cycle. The relationship between ovarian hormones and smoking behavior was evaluated considering the changes in sex hormones during menstrual the period, and the results showed an increase in the number of cigarettes smoked by women in their luteal phase compared to follicular phase (54). Allen et al. study results are aligned with this finding in which a significant correlation between smoking in luteal phase and PMS was discovered (55). No unhealthy behavior, except in two participants in each group, were observed in the present study, so it seems that the number of samples was not adequate to test this factor and the researcher believes that further studies are required in this respect. 


\section{Conclusions}

In summary, the findings showed that an appropriate lifestyle can reduce the severity of premenstrual syndrome. Functional significance of the findings is that changing lifestyle including proper eating habits, dietary changes, decreasing stress and unhealthy behavior, and other safe interventions can help reduce PMS symptoms. With attention to the negative effects of PMS on the quality of life, we must take steps to increase the female population's awareness of PMS and the appropriate lifestyle to reduce its occurrence and effects. Additional research conducted to compare a high-protein diet with high-fiber diet in the treatment of women suffering from premenstrual syndrome may be an interesting avenue for future research on this topic.

\section{Acknowledgments:}

This article was extracted from a research thesis by Maryam Mohebbi entitled "Comparison between the lifestyles of university students with and without premenstrual syndromes" approved by Shahid Beheshti University of Medical Sciences and supervised by Dr. Sedigheh Amir Ali Akbari. We appreciate the cooperation of the honorable Research Deputies at the University of Shahid Beheshti and Qazvin University as well as all of the female students who participated.

\section{Conflict of Interest:}

There is no conflict of interest to be declared.

\section{Authors' contributions:}

All authors contributed to this project and article equally. All authors read and approved the final manuscript.

\section{References:}

1) Bakhshani N, Hasanzadeh Z, Raghibi M. Prevalence of premenstrual symptoms and premenstrual dysphoric disorder among adolescents students of Zahedan. ZJRMS. 2012, 13(8): 29-34.

2) Pourmohsen M, Taavoni S, Zoneamat Kermani A, Hosseini F. Evaluation the effect of vitamin $E$ on premenstrual syndrome. Journal of Guilan University of Medical Sciences. 2010; 19(73): 73-9.

3) Gehlert S, Song $\mathrm{IH}$, Chang $\mathrm{CH}$, Hartlage SA. The prevalence of premenstrual dysphoric disorder in a randomly selected group of urban and rural women. Psychological medicine. 2009; 39(01): 129-36. doi: 10.1017/S003329170800322X. PMID: 18366818, PMCID: PMC2752820.

4) Ghalwa NA, Qedra RA, Wahedy K. Impact of Calcium and Magnesium Dietary Changes on Women Pain and Discomfort from Premenstrual Syndrome at the Faculty of Pharmacy-Gaza Strip. World Journal of Pharmacy and Pharmaceutical Sciences. 2014; 3(2): 981-1005.

5) Novak E, Berek J, Hillard P, Adashi E. Novak's gynecology. 13th ed. London: Lippincott Williams and wilkins. 2012; 397-401.

6) Phillips CH, Anthony F, Benyon C, Monga AK. Urogynaecology: Collagen metabolism in the uterosacral ligaments and vaginal skin of women with uterine prolapse. BJOG. 2006; 113(1): 39-46. doi: 10.1111/j.1471-0528.2005.00773.x, PMID: 16398770.

7) Domoney C, Vashisht A, Studd J. Premenstrual syndrome and the use of alternative therapies. Ann N Y Acad Sci. 2003; 997(1): 330-40. doi: 10.1196/annals.1290.036. PMID: 14644840.

8) Shahpoorian F, Mahmoodi Z, Hosseini F, Bastani F, Parsay S. Premenstrual syndrome (PMS) and the related symptoms among students of Iran University of Medical Sciences (IUMS). IJN. 2006; 18(44): 57 66.

9) Speroff L, Fritz MA. Clinical Gynecology Endocrinology and Infertility. 1th ed. Philadelphia: Lippincott Williams \& Wilkins. 2011; 573-82.

10) Tacani PM, Ribeiro Dde O, Barros Guimarães BE, Machado AF, Tacani RE. Characterization of symptoms and edema distribution in premenstrual syndrome. Int $\mathrm{J}$ Womens Health. 2015; 7: 297-303. doi; 10.2147/IJWH.S74251. PMID: 25792857, PMCID: PMC4362892.

11) Ramezani Tehrani F, Hashemi S, Robab Allameh M. Prevalence of premenstrual syndrome and some of its relative factors in reproductive age. Ofogh-e-Danesh. 2012; 18(3): 121-7.

12) Dickerson LM, Mazyck PJ, Hunter MH. Premenstrual syndrome. Am Fam Physician. 2003; 67(8): 174352. PMID: 12725453.

13) Braverman PK. Premenstrual syndrome and premenstrual dysphoric disorder. J Pediatr Adolesc Gynecol. 2007; 20(1): 3-12. doi: 10.1016/j.jpag.2006.10.007, PMID: 17289510. 
14) Ozgoli G, Shahveh M, Esmaielli S, Nassiri N. Essential oil of Citrus sinensis for the treatment of premenstrual syndrome; a randomized double-blind placebo-controlled trial. Journal of Reproduction \& Infertility. 2011; 12(2): 123-9.

15) Obeidat BA, Alchalabi HA, Abdul-Razzak KK, Al-Farras MI. Premenstrual symptoms in dysmenorrheic college students: prevalence and relation to vitamin D and parathyroid hormone levels. Int J Environ Res Public Health. 2012; 9(11): 4210-22. doi: 10.3390/ijerph9114210. PMID: 23202842, PMCID: PMC3524623.

16) Currie C, Molcho M, Boyce W, Holstein B, Torsheim T, Richter M. Researching health inequalities in adolescents: the development of the Health Behaviour in School-Aged Children (HBSC) family affluence scale. Soc Sci Med. 2008; 66(6): 1429-36. doi: 10.1016/j.socscimed.2007.11.024. PMID: 18179852.

17) Mcdonald S, Thompson C. Women's health. Australia: Elsevier. 2005; 90-121.

18) Mahmoodi Z, Shahpoorian F, Bastani F, Parsay S, Hoseini F. Comparison of the effect of carbohydrate rich supplement and diet on premenstrual syndrome. J Kermanshah Univ Med Sci. 2010; 14(1): 10-9.

19) Chocano-Bedoya PO, Manson JE, Hankinson SE, Willett WC, Johnson SR, Chason-Taber L, et al. Dietary B vitamin intake and incident premenstrual syndrome. Am J Clin Nutr. 2011; 93(5): 1080-6. doi: 10.3945/ajcn.110.009530. PMID: 21346091, PMCID: PMC3076657.

20) Dolatian M, Montazeri S, Valaei N, Ahmadi M. The comparison of vitamin B6 and vitamin E effects on premenstrual syndrome symptoms. J Zanjan Univ Med Sci Health Services. 2002; 9(37): 5-10.

21) Sharma P, Kulshreshtha S, Singh G, Bhagoliwal A. Role of bromocriptine and pyridoxine in premenstrual tension syndrome. Indian J Physiol Pharmacol. 2007; 51(4): 368-74. PMID: 18476391.

22) Jafarnejad F, Shakeri Z, Najafi MN, Salehi Fadradi J. Evaluation the relationship between stress and the risk of premenstrual syndrome. Iran J Obstet Gynecol Infertil. 2013; 16(76): 11-8.

23) Dolatian M, Mirabzadeh A, Forouzan AS, Sajjadi H, Majd HA, Moafi F, et al. Correlation between selfesteem and perceived stress in pregnancy and ways to coping with stress. Pajoohandeh Journal. 2013; 18(3): 148-55.

24) Bertone-Johnson ER, Hankinson SE, Johnson SR, Manson JE. Cigarette smoking and the development of premenstrual syndrome. Am J Epidemiol. 2008; 168(8): 938-45. doi: 10.1093/aje/kwn194. PMID: 18701443, PMCID: PMC2727205.

25) Freeman EW, DeRubeis RJ, Rickels K. Reliability and validity of a daily diary for premenstrual syndrome. Psychiatry Res. 1996; 65(2): 97-106. doi: 10.1016/S0165-1781(96)02929-0. PMID: 9122290.

26) Sedighi S, Amir Ali Akbari S, Afrakhteh M, Esteki T, Alavi Majd H, Mahmoodi Z. Comparison of lifestyle in women with polycystic ovary syndrome and healthy women. Glob J Health Sci. 2014; 7(1): 228-34. doi: 10.5539/gjhs.v7n1p228, PMID: 25560358, PMCID: PMC4796416.

27) Leung DY, Lam TH, Chan SS. Three versions of Perceived Stress Scale: validation in a sample of Chinese cardiac patients who smoke. BMC public health. 2010; 10: 513. doi: 10.1186/1471-2458-10-513. PMID: 20735860, PMCID: PMC2939644.

28) Shamsi M, Bayati A, Jahani F. Farhangnia L. The effect of Holy Quran recitation on perceived stress among personnel of Arak University of Medical Sciences. Daneshvar Medicine. 2011; 19(95): 35-44.

29) Hazavehei MM, Hosseini Z, Moeini B, Moghimbeigi A, Hamidi Y. Assessing stress level and stress management among Hamadan hospital nurses based on precede model. Horizon Med Sci. 2012; 18(2): 78 85.

30) Vahedian Azimi A, Asghari Jafarabadi M, Payami Bousari M, Kashshafi M. The Effect of Progressive Muscle Relaxation on Perceived Stress of Patients with Myocardial Infarction. ZUMS. 2012; 20(81): 1827.

31) Cohen S, Kamarck T, Mermelstein R. A global measure of perceived stress. J Health Soc Behav. 1983; 24(4): 385-96. doi: 10.2307/2136404. PMID: 6668417.

32) Velezmoro R, Lacefield K, Roberti JW. Perceived stress, sensation seeking, and college students' abuse of the Internet. Computers in Human Behavior. 2010; 26(6): 1526-30. doi: 10.1016/j.chb.2010.05.020.

33) Bastani F, Rahmatnejad L, Jahdi F, Haghani H. Breastfeeding self efficacy and perceived stress in primiparous mothers. Iran Journal of Nursing. 2008; 21(54): 9-24.

34) Rahman S, Parvez AK, Sabur A, Ali S. Study of the Effect of Food Habit, Lifestyle and Daily Trip on Physical and Mental Status of Subjects at Islamic University in Kushtia, Bangladesh. Open Journal of Statistics. 2012; 2(2): 219. doi: 10.4236/ojs.2012.22027.

35) Ransom SB. Contemporary therapy in obstetrics and gynecology. WB Saunders Company; 2002. 
36) Dehghan Manshadi F, Emami M, Ghamkhar L, Shahrokhi B, Ghanbari Z. The effect of a three-month regular aerobic exercise on premenstrual syndrome. Journal of Rafsanjan University of Medical Sciences. 2008; 7(2): 89-98.

37) Drife JO, Magowan B. Clinical obstetrics and gynaecology. Elsevier Health Sciences; 2004.

38) Neal D, Barnard MD. Nutritional Factors in Menstrual Pain and Premenstrual Syndrome. Physicians Committee for Responsible Medicine (PCRM). 2009.

39) Cross GB, Marley J, Miles H, Willson K. Changes in nutrient intake during the menstrual cycle of overweight women with premenstrual syndrome. $\mathrm{Br} \mathrm{J}$ Nutr. 2001; 85(04): 475-82. doi: 10.1079/BJN2000283. PMID: 11348562.

40) Gold EB, Bair Y, Block G, Greendale GA, Harlow SD, Johnson S, et al. Diet and lifestyle factors associated with premenstrual symptoms in a racially diverse community sample: Study of Women's Health Across the Nation (SWAN). J Womens Health (Larchmt). 2007; 16(5): 641-56. doi: 10.1089/jwh.2006.0202, PMID: 17627400.

41) Seedhom AE, Mohammed ES, Mahfouz EM. Life style factors associated with premenstrual syndrome among El-Minia University Students, Egypt. ISRN Public Health. 2013; 2013. doi: 10.1155/2013/617123.

42) Tabarroki S, Kargarnovin Z, Amiri Z, Tabarroki E, Ozgoli G. Influence of premenstrual syndrome on energy and nutrient intake. Journal of Shahid Beheshti School of Nursing \& Midwifery. 2012; 21(75): 37 44.

43) Trout KK, Basel-Brown L, Rickels MR, Schutta MH, Petrova M, Freeman EW, et al. Insulin sensitivity, food intake, and cravings with premenstrual syndrome: a pilot study. J Womens Health (Larchmt). 2008; 17(4): 657-65. doi: 10.1089/jwh.2007.0594. PMID: 18447765, PMCID: PMC3319142.

44) Bryant M, Truesdale K, Dye L. Modest changes in dietary intake across the menstrual cycle: implications for food intake research. Br J Nutr. 2006; 96(05): 888-94. doi: 10.1017/BJN20061931. PMID: 17092378.

45) Khodayarifard M, Parand A. Stress and coping styles. Tehran: University of Tehran Publications; 2006.

46) Al-Saleh SA, Al-Madi EM, Al-Angari NS, Al-Shehri HA, Shukri MM. Survey of perceived stressinducing problems among dental students, Saudi Arabia. Saudi Dent J. 2010; 22(2): 83-8. doi: 10.1016/j.sdentj.2010.02.007, PMID: 23960480, PMCID: PMC3723267.

47) Benedict C, Kern W, Schmid SM, Schultes B, Born J, Hallschmid M. Early morning rise in hypothalamicpituitary-adrenal activity: A role for maintaining the brain's energy balance. Psychoneuroendocrinology, 2009; 34(3): 455-62. doi: 10.1016/j.psyneuen.2008.10.010, PMID: 19038501.

48) Zarei Z, Bazzazian S. The relationship between premenstrual syndrome disorder, stress and quality of life in female students. Iranian Journal of Psychiatric Nursing. 2015; 2(4): 49-58.

49) Lustyk MKB, Beam CR, Miller AC, Olson KC. Relationships among perceived stress, premenstrual symptomatology and spiritual well-being in women. Journal of Psychology and Theology. 2006; 34(4): 311.

50) Cheng SH, Shih CC, Yang YK, Chen KT, Chang YH, Yang YC. Factors associated with premenstrual syndrome - a survey of new female university students. Kaohsiung J Med Sci. 2013; 29(2): 100-5. doi: 10.1016/j.kjms.2012.08.017. PMID: 23347812.

51) Gibbs SG, Karlan BY, Haney AF, Nygaard IE. Danforth's obstetrics and gynecology. 10th ed. Philadelphia, Williams \& Wilkins. 2008; 672-80.

52) Armand A, Talaee A. Investigating the Efficacy of Cognitive-Behavioral Stress-Management Training on Decreasing the Psychological Problems and Symptoms of Premenstrual Syndrome of Afflicted Women. Iranian Journal of Obstetrics, Gynecology \& Infertility. 2012; 15(21): 24-31.

53) Takeda T, Tadakawa M, Koga S, Nagase S, Yaegashi N. Premenstrual symptoms and posttraumatic stress disorder in Japanese high school students 9 months after the great East-Japan earthquake. Tohoku J Exp Med. 2013; 230(3): 151-4. doi: 10.1620/tjem.230.151. PMID: 23842447.

54) Sakai H, Ohashi K. Association of menstrual phase with smoking behavior, mood and menstrual phaseassociated symptoms among young Japanese women smokers. BMC women's health. 2013; 13(1): 10. doi: 10.1186/1472-6874-13-10, PMID: 23452831, PMCID: PMC3607846.

55) Allen SS, Allen AM, Pomerleau CS. Influence of phase-related variability in premenstrual symptomatology, mood, smoking withdrawal, and smoking behavior during ad libitum smoking, on smoking cessation outcome. Addict Behav. 2009; 34(1): 107-11. doi: 10.1016/j.addbeh.2008.08.009. PMID: 18818024, PMCID: PMC2615226. 